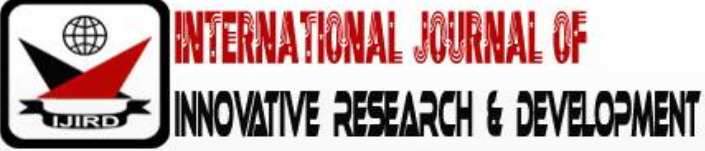

ISSN 2278 - 0211 (Online)

\section{The Effect of Monitoring and Evaluation on the Performance of Constituency Development Fund Projects in Elgeyo Marakwet, Kenya}

\author{
Paul Kurgat \\ Ph.D. Scholar Project Management, Jomo Kenyatta University of Agriculture and Technology, Kenya \\ Dr. Wario Guyo \\ Lecturer, Jomo Kenyatta University of Agriculture and Technology, Kenya
}

\begin{abstract}
:
Despite the benefits of M\&E, most projects take a longer time to be completed and end up not achieving their intended objectives hence unsustainable because sound M\&E practices were not observed. In the case of CDF projects, evidence released show funds are misappropriated, projects are incomplete, and those that are complete are poorly done.Elgeyo Marakwet County has been experiencing lack of proper utilization of the CDF funds, incomplete or poorly completed projects. Challenges in mismanagement of the $\mathrm{CDF}$ in this county are inclined towards poor project management that further converges in weaknesses in monitoring and evaluation of the CDF projects. It is under such a background that this study assessed the effect of monitoring and evaluation on the performance of CDF projectsin Elgeyo Marakwet. It was guided by the monitoring and evaluation theories and incorporated a descriptive study design. This allowed for purposive sampling as it only targeted the project managers and M\&E heads thereby selecting 65 respondents and ending up with a 53\% response rate which is adequate as per research standards. Findings revealed that indeed CDF projects in Elgeyo Marakwet had employed both monitoring and evaluation aspects in their implementation such as needs assessment, baseline studies, ascertaining of project effectiveness and sustainability. However recommendations were made to reinforce these processes for optimal performance. The CDF projects in Elgeyo Marakwet are concentrated in education related projects hence should also spread to other projects to ease over emphasis on educational projects. Further, the CDF projects should incorporate international best practices and standards to monitoring and evaluation if they are to achieve optimal project success.
\end{abstract}

Keywords: Projects, monitoring and evaluation, performance and project success

\section{Introduction}

The main reason why projects exist is to address a need in society for purposes of improving standards of living. Project practitioners come in to ensure that checks and balances are kept in line with the plan and periodically assess the project progress in relation to set plans (Project Management Institute, 2015). Data is also taken and analyzed to inform on performance of the project in terms of achieving its goal. The process of tracking and data collection and analyses is what is commonly referred to as monitoring and evaluation (PMI, 2015). Monitoring and evaluation tends to be taken as one thing but in real sense, they are in fact two different sets of firm's activities that are related but not similar (White, 2014). According to the author monitoring is that methodical collection and analysis of information as a project progresses. The author argues that it is aimed at enhancing the effectiveness and efficiency of a project and that it is based on set targets and planned actions throughout the planning phases of a project. There are four types of monitoring; input monitoring which is mainly for accountability as it establishes if resources that is human, financial and material are mobilized as planned, output monitoring which establishes if products or services are delivered as planned, process monitoring which reviews the processes by which a program is managed together with issues such as participation by primary and other stakeholders and finally impact monitoring which establishes if a program is having the expected effect and if not, what the required modifications are needed. Evaluation on the other hand, according to Olive (2012), is the assessment of real project impacts against established strategic plans. The author argues that it looks at what one is set out to do, what he/ she has accomplished and how it has been accomplished. Desmond (2011) in his study says that evaluation can be of two types, namely formative which means it takes place throughout the project life with the objective of enhancing the strategy or manner of the project functioning and summative which means that it draws ideas from completed projects whose stipulated cycle has come to close, though its outcomes might still be generating the project benefits to the beneficiaries. In addition, evaluation is used in confirming that the set direction is correct, and that correct mix of strategies and resources has been used to get there. It usually focuses on outcomes and their link with outputs. Monitoring and evaluation (M\&E) systems are very effective as project implementation tools in that they inform project managers whether or not the implementation is going as expected (White, 2014). It also informs whether project inputs, actions, 
outputs and external factors are taking place as planned and if corrective measures are required to adjust implementation plan. Focusing on the Constituency Development Fund (CDF) it is among the ingenious innovations of the National Rainbow Coalition (NARC) Government of Kenya. As opposed to the rest of development trends filtering from the Central Government through larger and additional layers of administrative organs and chains, the financial resources provided by the $\mathrm{CDF}$ is challenged directly to local level and hence provide people at the local level with a chance to make expenditure decisions,

Unlike other development trends that filter from Central Government through larger and more layers of administrative organs and bureaucracies, funds under this program go directly to local level and thus provide people at the grassroots the opportunity to make expenditure decisions that maximize their welfare consistent with the theoretical predictions of decentralization theory. The CDF is therefore an example that empowers local communities by providing funds often from the Central Government but sometimes from donor sources (CDF Act, 2003).In Kenya, debate around CDF funded projects have aroused mixed feelings some with success stories while others revolving around total project failure and this is due to an array of reasons. Studies like Odhiambo (2011), found that interpersonal skills were a significant competence required for, managing CDF projects especially maintaining project standards, planning and integrating. Munyori (2012), in his study found out that there was an unbalanced distribution of CDF projects upon all public primary schools in Starehe Constituency. Karanja (2013), found out that lack of coordination in supplies negatively affected project performance due to increased complexity and disagreement between supply chains. A gap exists when it comes to monitoring and evaluating these projects. It is under this background that this study endeavored to assess the effect of M\&E on performance of CDF projects in Elgeyo Marakwet.

\subsection{Statement of the Problem}

Rist (2009), argued that monitoring and evaluation is very important during project implementation as it keeps track of how the implementation is going on. The tool also ensure that project inputs, actions, outputs and external factors are occurring as expected and indicates if there is need for corrective measures to adjust the implementation plans. However, despite the benefits of $\mathrm{M \& E}$, most projects take a longer time to be completed and end up not achieving their intended objectives hence unsustainable because sound M\&E practices were not observed. In the case of CDF projects, evidence released show funds are misappropriated, projects are incomplete, and those that are complete are poorly done. According to a report by the National Anti-corruption Campaign Steering Committee, on-going projects lack serious monitoring and evaluation and has led to abuse of resources (KIPPRA, 2016). Inadequacy in M\&E of CDF projects has continued to persist and especially in Elgeyo Marakwet County. This county like many other parts of Kenya has been experiencing lack of proper utilization of the CDF funds, incomplete or poorly completed projects. Challenges in mismanagement of the CDF in this county are inclined towards poor project management that further converges in weaknesses in monitoring and evaluation of the CDF projects. This study was to assess the effects of M\&E in the performance of CDF projects in Elgeyo Marakwet County.

\subsection{General objectives}

The general objective of this study was to assess the effect of M\&E on the performance of CDF projects in Elgeyo Marakwet County, Kenya.

\subsubsection{Specific Objectives Were}

- To determine the effects of monitoring on the performance of CDF projects in Elgeyo Marakwet County.

- To find out the effects of evaluation on the performance of CDF projects in Elgeyo Marakwet County.

\subsubsection{The Study Sought to Answer the Following Questions}

- How does the performance of CDF projects in Elgeyo Marakwet County affected by project monitoring?

- What are the effects of evaluation on the performance of CDF projects in Elgeyo Marakwet County?

\subsubsection{Significance of the Study}

The findings of this study if adopted would be useful in various ways. It may enforce designing of new policies and interventions that may aid in fostering performance of CDF projects with regards to M\&E. Also, Elgeyo Marakwet may benefit by identifying what influences perceptions towards M\&E that hinder best practices in CDF project implementation then work towards managing them for successful intervention. To academics and practitioners it may build the body of knowledge of both project management and $\mathrm{M} \& \mathrm{E}$.

\subsubsection{Scope of the Study}

The researcher strived to conduct the study on CDF project staff in Elgeyo Marakwet. It wasideal since the researcher felt that $\mathrm{CDF}$ projects in the said region were sufficient in giving the necessary information required for the study. Also due to logistical issues that would be involved in going round all the National CDF projects and across borders, the researcher felt the data was a representative sample. The data was collected from the staff at CDF projects in Elgeyo Marakwet specially the project managers/ coordinators and Monitoring and Evaluation heads. 


\section{Literature Review}

\subsection{Theoretical Framework}

Theoretical framework is the structure that supports a theory of a research study (Bless \& Smith, 2008). The theoretical framework introduces and describes the theories that explain why the research problem under study exists (Bless \& Smith, 2008). The theoretical framework in this study was guided by the theory of monitoring and the theory of evaluation.

\subsection{Theory of Monitoring}

Monitoring is a tool in project management. It is among the tools that aid project managers with knowledge of when processes are proceeding as planned as well as in the event of change in conditions (Meyer, 2004). The supply the administration with relevant data for decision making as pertains to the project. Monitoring is important for all projects regardless of the size and complexity as it aids the identification of project areas that are on target as well as those requiring adjustment or replacement. Different forms of project need varied forms of monitoring systems as expressed by Shapiro (2011). Nevertheless, the most prominent monitoring systems among the project managers are those developed on M\&E matrix and on the basis of Logical Framework Approach to monitoring and evaluation (Welsh, et al. 2005). Monitoring is the process of regular and systematic collection, analysis as well as reporting of information concerning the project inputs, activities, outputs, outcomes and impacts (World Bank, 2011). The major focus in monitoring is attainment of efficiency and consequently setting the stage for fostered effectiveness of a project through providing the management and the rest of stakeholders with project progressive advancement as well as attainment of goals utilizing the available funds (World Bank, 2011). Hence, it keeps track of the project work and update the management in case things does not go as planned. Consequently, it is an invaluable tool for good management in addition to being an important base for evaluation. Monitoring is an internal function to a project that entails establishment of indicators, setting up information collection systems, collecting and recording, analysis of information, and utilization of information to inform day-to-day management (Shapiro, 2011). For instance, monitoring can inform whether processes are resource effective and if not then adjustments are done to ensure everything runs accordingly. There are four types of monitoring; input monitoring which is mainly for accountability as it establishes if resources that is human, financial and material are mobilized as planned, output monitoring which establishes if products or services are delivered as planned, process monitoring which reviews the processes by which a program is managed together with issues such as participation by primary and other stakeholders and finally impact monitoring which establishes if a program is having the expected effect and if not, what the required modifications are (Neil, 2012).

\subsection{Theory of Evaluation}

Conversely, evaluation denotes a scientific based appraisal of strengths as well as weakness of the project (Hunter, 2009). This means it is used in comparing between actual and planned. Evaluation is a way to check efficiency, effectiveness and impact of a project. Evaluation can be done in two way; evaluation conducted for an ongoing project also termed as formative evaluation, and evaluation conducted after project is completed, referred to as summative evaluations. Evaluation entails examining what the project intended to attain, assessment of progress with regard to what needed to be achieved, and bearing on target, examining the effectiveness of the project strategy. Examining the efficient utilization of resources, opportunity costs, as well as sustainability of the project, and implication for different stakeholders (Hunter, 2009 and Shapiro, 2011). Evaluation therefore entails both the efficiency and effectiveness aspects of project implementation. It is carried out for a number of reasons such as providing the project team and stakeholders including donors with information pertaining to the degree the project meet is objectives; building of transparency and accountability on the utilization of project resource; providing project staff with a clearer basis for decision making, as well as for planning purposes for future projects which may be guided by lessons from previous ones. Common types of evaluation form of evaluation are formative and summative entails sub-components making for a successful project evaluation(Torres \& Preskill, 2011). Formative evaluation entails an on-going process that make it possible for feedback to be implemented in the course of program cycles (Boulmetis \& Dutwin, 2015). Formative evaluation is more focused on the examination and changing of process as they occur, provision of timely feedback pertaining to program services and allowing for program adjustment to aid in the attainment of goals. Common forms of formative evaluation encompass need assessment which determines the beneficiaries of the program, their level of need, and what will work in meeting this need; structured conceptualization which assist the concerned parties define the program, the target populous, and the possible results; implementation evaluation which monitors the faithfulness of the program delivery and process evaluation that assess the process of delivering the program entailing the delivery procedures (Boulmetis \& Dutwin, 2015). Summative evaluation happens at the end of the program cycles and gives a general examination of the program effectiveness (Boulmetis \& Dutwin, 2015). Summative evaluation on the other hand assess the program outcomes with a view to determining its general effectiveness. It is a method that requires to establish whether program objectives were met; whether there is need for improvement and modification of the overall structure of the program, determine the overall impact of the program, whether there is need for additional resources to the address the program's weaknesses. Summative evaluation make it possible for practitioners to make decision pertain tp specific services and the future direction of the program that cannot be made when the program is ongoing. They need to be provided to funders as well as constituents who have interests in the project (Boulmetis \& Dutwin, 2015). Some example of popular summative evaluation are; goal-based evaluation which establish whether intended goals of a program are attained, Outcome evaluation explores if the project lead to demonstrable impacts on specifically established target results; Impact 
evaluation is wide-ranging and make assessment of the general or net effects, of the project; cost effective as well as cost benefit evaluation examines whether efficiency was attained through standardization of outcomes with regard to their monetary costs and values (Boulmetis \& Dutwin, 2015). Entities are increasingly evaluating the manner in which evaluation can attain increased consistency and effectiveness that is where it would allow for judgment of the impact of a project in addition to obtaining recommendation pertaining to future interventions. This enables a rigorous and robust evaluation system that is geared towards improved level outcomes and therefore sustainability (UNDP, 2009).

\subsection{Conceptual Framework}

Donald (2006) defines a conceptual framework as "a diagrammatical representation of dependent variables and independent variables." Mugenda and Mugenda (2003) defined an independent variable as "a variable that the researcher manipulates in order to determine its effect or influence on the dependent variable."'A dependent variable is caused by the independent variable and indicates the influence arising from the effects of independent variables" (Mugenda \& Mugenda, 2003). The independent and dependent variable were linked in the following framework.

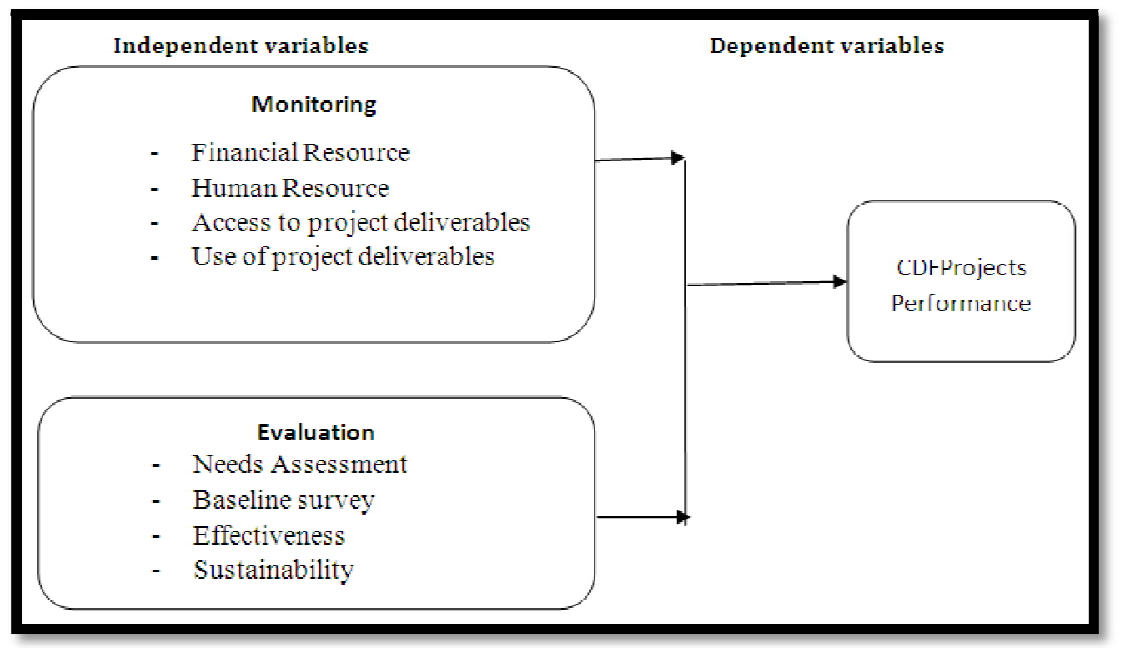

Figure 1: Conceptual Framework

Source: Author (2018)

\section{Research Methodology}

Kombo \& Tromp (2006) define research methodology as "the approach by which the meaning of data is extracted and is a continuous process." The research methodology provides the direction to be followed to get responses to the issues being examined. The present chapter represents the methodology adopted by the researcher in answering the research questions of the study. The chapter explores the research design, study population, sample size and method, data collection, data analysis method as well as the research ethics. It presents an outline on the manner the researcher carried out the study from data collection to analysis as well as conclusion drawn from the findings.

\subsection{Research Design}

Research design denotes the plan, structure as well as strategy of investigation conceived for purposes of obtaining responses to the research questions and control of variance. Stringer (2008), describes research design as "a procedure that provides answers to issues such as techniques to use to gather data, the kind of sampling strategies and tools to be used, and how time and cost constrain was dealt with." The present study adopted a descriptive research design as it closely examined as well as determined data and reported information within a particular context.

\subsection{Target Population}

Mugenda and Mugenda (2003), define a target population as "a group of individuals to which the researcher would like to generalize his/her results from."In the present study, the target population were project managers/coordinators and CDF committee members in all the Elgeyo Marakwet sub-counties' CDF projects being implemented. In Keiyo South they are $140 \mathrm{CDF}$ projects, $196 \mathrm{CDF}$ projects in Marakwet West, 176 CDF projects in Marakwet East and138 CDF projects in Keiyo North. This made a total of 650 CDF projects currently running.

\subsection{Sample and Sampling Techniques}

The present study adopted purposes sampling technique where sample selection is dependent on the discretion of the researcher as pertains to issues such as the type of respondents required in the study (Chandran, 2004). It is thus a sampling method that entails subjects selected based on specific characteristics and remove the ones not meeting set criteria. According to Cooper and Schindler (2003), this sampling method entails selecting respondents as per the judgment of the researcher, on the basis of expert knowledge of the respondent on the area being studied. The samples of research participants are indicated in Table 1 below. The study selected 65 respondents purposively selected from 9 varied sectors in the County Government. According to Kothari (2004), a sample size of between 10 and 30 percent of the entire population is considered representative and can be utilize in coming up with reliable findings that are generalizable 
to the whole population and therefore a sample of 65 was suitable since it consist of $10 \%$ of the population. In specific terms, the researcher narrowed down to project managers, coordinators as well as CDF committee member of CDF projects.

\begin{tabular}{|c|c|c|}
\hline Categories & Percentage \% & Sample \\
\hline Project Managers/ Coordinators & $47.1 \%$ & 30 \\
\hline CDF Committee Members & $52.9 \%$ & 35 \\
\hline Total & $100 \%$ & 65 \\
\hline
\end{tabular}

Table 1: Sample Size

\subsection{Data Collection Methods and Instruments}

Data collection instrument denotes the device that specified as well as objectifies the data collecting process. As expressed by Mugenda and Mugenda (2008), a researcher must develop instruments for purposes of collecting data. Among the most utilized instruments are questionnaires, interview, schedules, observational forms as well as standardized tests (Chandran, 2005). Questionnaires denotes a series of written questions on a topic which seeks the views of the respondents on a given issue. The present study adopted primary data collection method with the use of questionnaires. The questionnaires used contained closed ended questions and Likert scale methodology all briefly stated as well as well-focused recognition of the busy schedule for the respondents. The structured questions are usually closed ended with candidates provided with alternatives where to choose the most appropriate responses. The questionnaires were presented to the respondents under a forwarding letter accompanied by an introduction letter.

\subsection{Pilot Study}

A pilot study, also referred to as feasibility study, denotes a mini-version of a full-scale study or trial conducted as the researcher prepares for the actual study. Pilot testing refers to the measurement of dependent variable amid other subjects (Gravetter \& Forzano, 2008). It aims at ensuring the items in the instrument are categorically stated and portray similar meaning to the respondents. Pilot tests examines possible flaws in the measurement procedures as well as in the operationalization of variables (Mugenda \& Mugenda, 2003). Only pre-testing gives the researcher the ability to assess the ease the ease of use of the instrument. Any sensitive, confusing, or biased items are identified and modified or omitted. Pre-testing allows for refinement prior to the final test (Cooper \& Schindler, 2003). The pilot study for the present study provided a chance for the researcher to revise scripts, examine control measures, in addition to scanning the environment for factors that may confound the results. Hence, the researcher pre-tested the questionnaires in advance.

\subsection{Validity}

The study embraced content validity which illustrates whether the tests items are representative of the content designed to be measured by the test (Gravetter \& Forzano, 2008). The pilot study aided in determination of accuracy, clarity and sustainability of instruments. It further aided in identification of insufficient and ambiguous items including those that failed to evaluate the variables. Such items were either modified or disregarded entirely and new items adopted. Gall et al. (2006) points out that content experts aids in determining content validity.

\subsection{Reliability}

Reliability was utilized for the assessment of consistency of a test across time. The type of reliability made the assumption that there was no change in the quality or construct being evaluated. Reliability can be enhanced through inclusion of numerous similar items on a measure, through testing a diverse sample of individuals and utilization of uniform testing procedures. It is normally utilized as pertains to the question whether the measures that are devised for concepts in business are unswerving (Kothari, 2004). Cronbach's alpha on the basis of internal consistency was calculated with the use of statistical package for social studies tool for analysis (SPSS V. 24) in the determination of the reliability of the instrument. The method assess the average measurable items as well as their correlation. According to Kothari (2004), Cronbach alpha value of at least 0.70 suffices for a reliable research instrument. The Cronbach's Alpha value for this study was 0.79: an indication that the internal consistency of the items under measurement were considered to be good.

\subsection{Data Analysis and Presentation}

Data analysis denote the process of bringing order, structure and meaning to the mass of information collected. The process entails examination of what has been gathered and deducting and inferring (Kombo \& Tromp, 2006). The quantitative data that was obtained from the questionnaires was coded and keyed into statistical package of social science (SPSS V. 24) analysis software. Data collected was first coded as per the variables, then data entry done for every research tool filled after which descriptive statistics was carried out and presented in tabulations in form of frequencies, percentages and co-efficients.

\subsection{The Analytical Model}

The study engaged a regression analytical model to establish the link between the dependent and independent variables as indicated below:

$\left(\right.$ CDF Project Performance P $_{j}=\beta_{0}+\beta_{1}(\mathrm{M})_{1}+\beta_{2}(\mathrm{E})_{2}+$ Error term $)$ 
Where:

CDF Project Performance $=$ Depicts the dependent variable

$\mathrm{M}$

$=$ Monitoring

$\mathrm{E}$

=Evaluation

\section{Data Presentation, Analysis, and Interpretation}

This chapter dealt with information on the data collected, processed and analyzed using SPSS version 24. It had information relating to the quantitative data processed, analyzed and interpreted especially the findings from the descriptive and inferential statistics. This research study sampled 65project managers/ coordinators and CDF committee Members. Out of the targeted respondents, 35 were able to respond. This made a response rate of $53 \%$. According to Mugenda and Mugenda (2003) a 50\% response rate is adequate, and a response rate greater than $70 \%$ is very good. Hence the response rate in this study was adequate.

\subsection{Socio Demographic Characteristics}

Information on this aspect was related particularly to Gender of the respondents, sub-county they come from, CDF project they were involved in and the position they held in the project. These details were discussed each one separately in the following sections. The study sought to find out the Gender of the respondents. From the findings it came out clearly that the male gender was the majority going by $72 \%$ (25) of the response while the female were $28 \%$ (10). This is an indication that both genders were well represented in this study. The study next sought to find out the Sub-county the respondents came from. Findings revealed that majority of them came from Marakwet East 34\% (12). They were closely followed by those from Marakwet West 30\% (11) then those from Keiyo North 20\% (7) and finally those from Keiyo South $16 \%(5)$. The higher response in Marakwet East and West could be explained by the high number of CDF projects in the area as compared to Keiyo North and South.

\subsection{CDF Projects}

There was also need to establish which CDF project the respondents worked in. From the findings it came out evidently clear that the majority of the respondents worked in educational related projects in the four sub-counties (18), closely followed by those who worked in Health projects (9) then those working in water and sanitation projects (5) and finally (3) in administrative projects. This is an indication that the County government has placed emphasis on education in the county; an implication that also more CDF resources have been channeled the same way. At a moderate level the same can be said for Health projects.

\subsection{Respondents Position in the CDF Project}

The study found out the positions the respondents held in the CDF projects. From the findings it is was evident that the majority were Project Managers/ Coordinators 54\% (19) while CDF committee members were $46 \%$ (16). This is an indication that both levels of project management were well presented and thus can be implied they articulated the research questions as required.

\subsection{Effects of Monitoring on the Performance of CDF Projects}

The effects of monitoring on the performance of CDF projects was sought through responses on various aspects related to monitoring. From the findings, it was revealed that $94 \%$ (33) were conversant with project monitoring while $6 \%$ (2) were not. This is an indication that project monitoring is common in CDF projects in Elgeyo Marakwet County and the percentage that responded to the negative can easily be handled as an over sight. The table 2 presents these findings

\begin{tabular}{|c|c|c|}
\hline Response & Percentage (\%) & Frequency \\
\hline Yes & 94 & 33 \\
\hline No & 6 & 2 \\
\hline Total & 100 & 35 \\
\hline
\end{tabular}

Table 2: Conversant with Project Monitoring

The study sought to find out the degree upon which the respondents agreed to the various aspects related to monitoring previously subjected to. (On a scale of 1-5 where $1=$ strongly disagree, $2=$ Disagree, $3=$ Neutral, $4=$ Agree and $5=$ strongly agree). From the findings it came out clearly that $100 \%$ (35) were aware that assessing of financial resources allocated to a project is part of project monitoring. 97\% (34) agreed that assessing use of project deliverables was also part of project monitoring and a further 92\% (32) were in agreement that project monitoring entails assessing human resources utilized in a project. From the findings it can be implied that generally the respondents agreed to a large extent that there is project monitoring in Elgeyo Marakwet CDF projects. This is an implication that there is regular and systematic collection, analyzing and reporting information about a CDF project's inputs, activities, outputs, outcomes and impacts at Elgeyo Marakwet. Findings are shown in table 3. 


\begin{tabular}{|c|c|c|c|c|c|c|}
\hline Response & $\mathbf{5}$ & $\mathbf{4}$ & $\mathbf{3}$ & $\mathbf{2}$ & $\mathbf{1}$ & Total (\%) \\
\hline $\begin{array}{c}\text { Assessing of financial resources } \\
\text { allocated to a project }\end{array}$ & $74.0(26)$ & $26.0(9)$ & $0(0)$ & $0(0)$ & $0(0)$ & $100(35)$ \\
\hline $\begin{array}{c}\text { Assessing human resources } \\
\text { utilized in a project }\end{array}$ & $69.0(24)$ & $23.0(8)$ & $9.0(3)$ & $0(0)$ & $0(0)$ & $100(35)$ \\
\hline $\begin{array}{c}\text { Assessing access to project } \\
\text { deliverables }\end{array}$ & $17.0(6)$ & $60.0(21)$ & $14.0(5)$ & $9.0(3)$ & $0(0)$ & $100(35)$ \\
\hline $\begin{array}{c}\text { Assessing use of project } \\
\text { deliverables }\end{array}$ & $86.0(30)$ & $11.0(4)$ & $3.0(1)$ & $0(0)$ & $0(0)$ & $100(35)$ \\
\hline
\end{tabular}

Table 3: Extent of agreement on Project Monitoring

\subsection{Effects of Evaluation on the Performance of CDF Projects}

The study established whether the respondents were conversant with project evaluation. From the findings all respondents agreed to the affirmative that they were aware of project evaluation. Table 4 shows the results.

\begin{tabular}{|c|c|c|}
\hline Response & Percentage (\%) & Frequency \\
\hline Yes & 100 & 35 \\
\hline No & 0 & 0 \\
\hline Total & 100 & 35 \\
\hline
\end{tabular}

Table 4: Conversant with Project Evaluation

The research prompted for aspects related to project evaluation through certain statements. From the findings, all100\% (35) of the respondents responded to the affirmative that conducting a baseline survey is part of the evaluation process in the CDF projects. 98\% (34) agreed that ascertaining project effectiveness is part of the evaluation process. Further, 96\% (33) agreed that ascertaining project sustainability is part of the evaluation process and finally $92 \%$ (32) were of the opinion that conducting a needs assessment is part of Elgeyo Mrakwet's CDF project evaluation. From the foregoing it can be deduced that project evaluation is part of the CDF projects evaluation process going by the various components identified by the respondents. Table 5 presents the results.

\begin{tabular}{|c|c|c|c|}
\hline Response & Yes & No & Total \\
\hline Conducting a needs assessment & $92 \%(32)$ & $8 \%(3)$ & $100 \%(35)$ \\
\hline Conducting a Baseline survey & $100 \%(35)$ & $0(0)$ & $100 \%(35)$ \\
\hline Ascertaining project effectiveness & $98 \%(34)$ & $2 \%(1)$ & $100 \%(35)$ \\
\hline Ascertaining project sustainability & $96 \%(33)$ & $4 \%(2)$ & $100 \%(35)$ \\
\hline
\end{tabular}

Table 5: Statements related to project evaluation

The study further sought to find out the degree upon which the respondents agreed to the various aspects related to evaluation previously subjected to. (On a scale of 1-5 where1=strongly disagree, $2=$ Disagree, $3=$ Neutral, $4=A g r e e ~ a n d ~ 5=$ strongly agree). From the findings it came out clearly that $100 \%$ (35) agreed that conducting a needs assessment is an aspect of project evaluation at Elgeyo Marakwet. 98\% (34) agreed that conducting a baseline survey was part of project evaluation in their respective CDF projects. Further, 94\% (33) were in agreement that ascertaining project effectiveness was part of project evaluation and finally $88 \%$ (31) were in agreement that project evaluation at Elgeyo Marakwet incorporated ascertaining project sustainability. This was an indication that to a large extent project evaluation is part of project implementation at Elgeyo Marakwet CDF projects. It could be implied that in the CDF projects in Elgeyo Marakwet appraisal is done for strengths and weaknesses of the project and in turn caters for efficiency, effectiveness and impact of the project outcomes. Findings are shown in table 6.

\begin{tabular}{|c|c|c|c|c|c|c|}
\hline Response & $\mathbf{5}$ & $\mathbf{4}$ & $\mathbf{3}$ & $\mathbf{2}$ & $\mathbf{1}$ & Total (\%) \\
\hline Conducting a needs assessment & $88.0(30)$ & $12.0(5)$ & $0(0)$ & $0(0)$ & $0(0)$ & $100(35)$ \\
\hline Conducting a Baseline survey & $92.0(32)$ & $6.0(2)$ & $2.0(1)$ & $0(0)$ & $0(0)$ & $100(35)$ \\
\hline Ascertaining project effectiveness & $88.0(31)$ & $6.0(2)$ & $6.0(2)$ & $0(0)$ & $0(0)$ & $100(35)$ \\
\hline Ascertaining project sustainability & $52.0(18)$ & $36.0(13)$ & $12.0(4)$ & $0(0)$ & $0(0)$ & $100(35)$ \\
\hline
\end{tabular}

Table 6: Extent of agreement on Project Evaluation

\subsection{Regression Analysis}

To establish the relationship between CDF project performance in Elgeyo Marakwet and monitoring and evaluation of the same projects, a multiple regression analysis was conducted. The regression model used was as follows; $Y=\alpha+\beta_{1} X_{1}+\beta_{2} X_{2}+\varepsilon$

Where: $Y=$ CDF Project Performance, $\alpha=$ Constant, $\beta_{1}=$ Co-efficient for Monitoring and $\beta_{2}=$ Co-efficient for Evaluation.

Determination coefficient $\mathrm{R}$ squared $\left(\mathrm{R}^{2}\right)$ was carried out to determine the proportion of the variation in dependent variable that is attributed to the changes in the explanatory variables. The study established $\mathrm{R}^{2}$ of 0.651 which implies that $65.1 \%$ of the variation in CDF Project Performance is attributed to the changes in explanatory variables (Project 
Monitoring and Evaluation). It means that the goodness of fit test is adequate. A correlation coefficient of 0.806 depicts there is a good linear dependence of CDF Project Performance, Project monitoring and Evaluation hence a strong correlation between the dependent variable (CDF Project Performance) and independent variables (Project Monitoring and Project Evaluation).

\begin{tabular}{|c|c|c|c|c|}
\hline Model & R & R Square & Adjusted R square & Std. Error of the estimate \\
\hline 1 & $.806^{\mathrm{a}}$ & .651 & .619 & .34567 \\
\hline
\end{tabular}

Table 7: Model summary

\begin{tabular}{|c|c|c|c|c|c|}
\hline Model & \multicolumn{2}{|c|}{ Unstandardized Coefficients } & \multicolumn{3}{c|}{ Standardized Coefficients } \\
\hline & $\mathrm{B}$ & Std. Error & Beta & $\mathrm{T}$ & Sig. \\
\hline (Constant) & 0.049 & 0.045 & & 1.071 & 0.097 \\
\hline Project Monitoring & 0.041 & 0.025 & 0.258 & 1.612 & 0.024 \\
\hline Project Evaluation & 1.704 & 0.507 & 0.573 & 3.361 & 0.003 \\
\hline
\end{tabular}

Table 8: Regression coefficient results

a. Predictors: (constant), Project Monitoring, Project Evaluation

b. Dependent Variable: CDF Project Performance

Source: Research findings

Hence the model: $\mathrm{Y}=0.049+0.041 \mathrm{X}_{1}+1.704 \mathrm{X}_{2}$

The above model shows that when all other variables have a value of zero then the CDF Project Performance is 0.049. A unit increase in project monitoring translates to 0.041 increase in CDF Project Performance, also a unit increase of Project Evaluation translates to 1.704 increase in CDF Project Performance. This is an indication that project monitoring and project evaluation affect the CDF Project Performance. Findings also show that the critical values attained are statistically significant at $5 \%$ level of significance.

\section{Summary, Conclusion and Recommendations}

The content herein is based on the two objectives which guided the study. These objectives were: To determine the effects of monitoring on the performance of CDF projects in Elgeyo Marakwet County and to find out the effects of evaluation on the performance of CDF projects in Elgeyo Marakwet County.

\subsection{Effects of Monitoring on the Performance of CDF Projects}

Findings reveal that majority of the respondents were aware of project monitoring aspects. 98\% (34) were aware that assessing of financial resources allocated to a project was part of project monitoring, a further $96 \%$ (33) were aware that both assessing human resources utilized in a project and assessing use of project deliverables are aspects of project monitoring. A further 90\% (31) were aware that assessing access to project deliverables was also an aspect of project monitoring.

It can be implied that the respondents were aware of aspects relating to project monitoring. Further it is an indication that there is regular and systematic collection, analyzing and reporting information about a CDF project's inputs, activities, outputs, outcomes and impacts at Elgeyo Marakwet. The findings could imply that CDF projects at Elgeyo Marakwet emphasize on efficiency which in turn sets the stage for effectiveness in a project. As is in line with the World Bank (2011), this provides the management and stakeholders with project progressive development and achievement of objectives within allocated resources. Shapiro (2011) adds that such kind of monitoring can inform whether processes are resource effective and if not then adjustments are done to ensure everything runs accordingly.

\subsection{Effects of Evaluation on the Performance of CDF Projects}

From the findings, $100 \%$ (35) of the respondents responded to the affirmative that conducting a baseline survey is part of the evaluation process in the CDF projects. 98\% (34) agreed that ascertaining project effectiveness is part of the evaluation process. Further, 96\% (33) agreed that ascertaining project sustainability is part of the evaluation process and finally $92 \%$ (32) were of the opinion that conducting a needs assessment is part of Elgeyo Mrakwet's CDF project evaluation. From the foregoing it can be implied that project evaluation is part of the CDF projects evaluation process going by the various components identified by the respondents. Further, this could mean that project managers and stakeholders including donors are provided with information on the extent to which the projects are meeting their objectives. It could also mean that to some extent there is transparency and accountability on the use of project resources which in turn provides project staff with a clearer basis for decision. As added by Boulmetis \& Dutwin, 2015) such evaluation processes give way for future project planning and development which is improved when guided by lessons learned from project experience.

\section{Conclusions}

The study concludes that the CDF projects in Elgeyo Marakwet have adopted project monitoring in their project interventions. It can also be inferred that resource assessments are done in the monitoring process that is both human and financial resource monitoring. The researcher also concludes that not only is access to project deliverables monitored but also the use of the deliverables by the primary beneficiaries. The study concludes that there is project evaluation done in 
the CDF projects in Elgeyo Marakwet. The study further concludes that project evaluation of the CDF projects not only determines who needs the program but also how great the need is and what might work to meet the need hence a needs assessment. The study also concludes that before project commencement, feasibility studies are done to assess the situation so as to act as a benchmark hence a baseline survey. The researcher also deduces that the project evaluation at the CDF projects in Elgeyo Marakwet incorporates a process geared towards project effectiveness and sustainability.

\section{Recommendations}

The study recommends that the CDF projects to enhance their monitoring and evaluation processes to operate at optimal levels. It is also recommended that the CDF projects in Elgeyo Marakwet should spread its resources to other projects to ease over emphasis on Educational projects. The study also recommends that the CDF projects should incorporate international best practices and standards to monitoring and evaluation for optimal project success. There is also need by the County government of Elgeyo Marakwet to foster the right project culture and perception towards Monitoring and Evaluation interventions.

\section{Areas for Further Research}

Studies could be done focusing on the different types of monitoring and evaluation on CDF project interventions to determine which is more effective to be adopted or duplicated. Another study could be done focusing on participatory monitoring and evaluation techniques to involve the primary beneficiaries who are the county citizens. A study could also be done focusing on other critical project success factors other than monitoring and evaluation. Further study could also be done employing a different research methodology and involve other projects besides CDF projects.

\section{References}

i. Bless,C. \& Higson-Smith, Q. (2008) Fundamentals of Social Research Methods: An African Perspective, Cape Town, Creda Press.

ii. Boulmetis, J., \& Dutwin, P. (2015).The ABCs of evaluation: Timeless techniques for program and project managers(2nded.). San Francisco, CA: Jossey-Bass.

iii. Chandran, E. (2004).Research Methods: A Quantitative Approach with Illustrations from Christian\Ministries. Daystar University. Nairobi.

iv. Cooper, R., \& Schindler, P., S. (2006).Business research methods. (10th.ed.). New York: McGraw-Hill.

v. Desmond, M. (2011).Habitat Restoration Effectiveness Monitoring for the Western Oregon Stream Project. Oregon Department of Fish and Wildlife, Portland, Oregon. Monitoring Program Report Number OPSW-ODFW-2001-07.

vi. Donald, N. (2006). Completing your thesis: A practical guide. Pretoria: Van Schaik Publishers.

vii. Gravetter, F. J., \& Forzano, L. B. (2008).Research methods for the behavioural sciences. Belmont, CA: Wadsworth Cengage Learning.

viii. Government of Kenya (2003). Kenya's Constituency Development Fund (CDF) Act, of 2003. GoK. Government Press, Nairobi.

ix. Hunter, J. (2009). Monitoring and Evaluation. Are we making a difference? Namibia Institute for Democracy.

x. Karanja, S. (2015). Efficiency and Efficacy of Kenya's Constituency Development Fund; Theory and Evidence; Working Paper 2005-42.

xi. Kothari, C. (2004). Research methodology-Methods \& Techniques, 2nd Edition, New Age International Ltd. Publisher, New Delhi, India. 1-23, 34-35,95-121.

xii. Kombo, D. K., \& Tromp, D. (2006). Proposal and Thesis Writing: An Introduction.Pauline's Publications' Africa, Nairobi.

xiii. Meyer, M. (2004). Managing Human Resource Development: an outcomes-based approach (2 ${ }^{\text {nd }}$ Ed). Durban: LexisNexis Butterworth's.

xiv. Mugenda, O. \& Mugenda, A. (2003). Research Methods; Quantitative and Qualitative Approaches,. Nairobi, Kenya.: Acts Press.

xv. Munyori, C.M. (2012). The Influence of CDF projects on Public Primary School Performance in Kenya. Nairobi County. Unpublished MBA Thesis, University of Nairobi.

xvi. Neil, M. (2012). Designing and Managing a Research Project: A business student's guide, Sage, the USA.

xvii. Odhiambo, F. (2011). Factors Influencing Management of CDF Projects A Case of Ainamoi Constituency, Kericho County. Unpublished Thesis.

xviii. Olive, D. (2012). Monitoring and Evaluating Agricultural Research. Cambridge: The University Press.

xix. Preskill, H. \& Torres, R. (2011). Evaluative inquiry for learning in organizations. Thousand Oaks, CA: Sage.

xx. PMI (2015). A Guide to the Project Management Body of Knowledge. Newtown Square, PA: Project Management Institute.

xxi. Rist, R. (2009).Company -wide project management: planning and control of programs of projects of different types. International Journal of project management, 17(1):55-59).

xxii. Shapiro, J. (2011). Monitoring and Evaluation, CIVICUS. Retrieved from: https:// civicus.org/ view/ media/ Monitoring\%20and\%20Evaluation.pdf

xxiii. Stringer, E. T. (2008). Action research in education (2nd Ed.). New Jersey: Pearson.

xxiv. UNDP (2009). Handbook on Planning, Monitoring and Evaluating for Development Results.UNDP, USA.

xxv. Welsh, N., Schans, M. \& Dethrasaving, C. (2005).Monitoring and Evaluation Systems Manual (M\&E Principles).Publication of the Mekong Wetlands Biodiversity Conservation and Sustainable Use Program.

xxvi. White, S. (2014). Participatory approaches and the measurement of human well-being. Esrc Research Group. UNUWider.

xxvii. World Bank (2011).Monitoring \& Evaluation: some tools, methods and approaches, The World Bank, Washington, D.C. 